\title{
SALADO Y SECADO SOLAR DE TILAPIA (Oreochromis sp) EN LA REGION DE SAN MARTIN
}

O. W. Mendieta $\mathrm{T}^{*}$

M. L. Medina V.*

\section{RESUMEN}

El presente trabajo trata sobre el salado y secado solar de filetes de tilapia (Oreochromis sp.). El pescado, en óptimas condiciones de frescura, fue descamado y fileteado. Luego se colocó los filetes en salmuera saturada preparada con un peso de sal equivalente al $40 \%$ del peso de los filetes.

Durante el salado, los contenidos de humedad y de cloruro de sodio fueron determinados con intervalo de 1 hora. Luego de 16 horas, el cloruro de sodio alcanzó una concentración de $17.6 \%$ en el músculo de tilapia, permaneciendo casi constante hasta las 24 horas de inmersión. El contenido de humedad fue inversamente proporcional al contenido de cloruro de sodio.

El secado de la tilapia salada fue realizado en un secador solar modelo cabina con circulación del aire por convección natural. Las variaciones en el contenido de humedad fueron controladas por medio de pesadas con intervalos de 1 hora. La temperatura del aire de secado se la determinó mediante psicrométros instalados en la cabina del secador. El producto final fue colocado en bolsas de polietileno y almacenado en condiciones ambientales.

La tilapia seco salada, evaluada organolépticamente, fue de óptima calidad y comparada favorablemente con el pescado seco salado elaborado en la zona empleando métodos tradicionales. El recuento de bacterias halófilas y coliformes arrojó resultados negativos. Los contenidos de humedad, ceniza, cloruro de sodio, proteínas, grasa y la capacidad de rehidratación tuvieron los siguientes valores: 25.0, $33.7,32.2,37.0,4.3$ y 45.0 por ciento respectivamente.

Palabras claves: Tilapia, salado, salmuera, secado solar, Selva alta. Perú.

Universidad Nacional de San Martín. Facultad de Ingeniería Agroindustrial. Casilla Postal .239. Tarapoto. 


\section{INTRODUCCIÓN}

El proceso de conservación por salado es una técnica antigua que tiene grandes posibilidades de éxito en nuestro país, especialmente en las regiones donde la comunicación es difícil y un sistema de refrigeración se hace imposible por razón de costos. Actualmente este proceso se efectúa en la Región San Martín empleando métodos tradicionales, en escala artesanal. El método tradicional utilizado corrientemente, corresponde al conocido como salado en pila seca, MIPE, IMARPE señalan 3 tipos de salado: 1. Salado en pila seca; 2 . salado en pila húmeda; y 3. salado en salmuera. Esta operación toma generalmente de uno o dos días, tiempo durante el cual se genera una considerable alteración enzimática y bacterial en el tejido muscular. Esto se debe, en parte, al método de salado empleado, en el cual es lenta la difusión de sal en el tejido, dando tiempo suficiente para que progresen las alteraciones mencionadas (Moncada, 1978; Moncada y Sarmiento, 1982). Sánchez y Lam (1965) y Lupin (1978) recomiendan el método de salado seco, para especies magras o de bajo contenido graso, siendo preferible el método de salado en salmuera para las especies grasas o semigrasas como en el caso de especies de aguas continentales (Moncada, 1982).

El pescado, terminado el salado, tiene un contenido de humedad entre $50 \mathrm{y}$ $60 \%$, debiendo someterse a la operación de secado como requisito para una buena conservación (Moncada y Sarmiento 1989; Hitzchky y Nunes, 1986). Dentro del método tradicional empleado en la región, el secado es realizado a la intemperie acentuándose las alteraciones producidas durante el salado debido a la acción directa de la luz solar y en general por las desventajosas condiciones ambientales haciéndose necesario recoger el pescado cuando la humedad relativa es alta o cuando se presenta tiempo lluvioso. Un método alternativo es la utilización de secadores solares.

No se han reportado experiencias para secado de pescado salado mediante el empleo de secadores solares, siendo en cambio abundantes para productos agrícolas (Espeleta et al, 1983; Marconde, 1980; Dorfman et al., 1981; Granados, 1982; Carbonell et al., 1985).

El presente trabajo se desarrolló con la finalidad de mejorar la metodología artesanal seguida para el salado y secado, demostrar la factibilidad del empleo de secadores solares para el secado de pescado así como difundir esta tecnología en la zona de selva alta. 


\section{MATERIALES Y METODOS}

La materia prima utilizada en el presente trabajo Consistió en especimenes de tilapia (Oreochromis sp) obtenidos en la piscigranja del Ministerio de Pesquería (Ahuashiyacu, Tarapoto), en 3 ensayos con $10 \mathrm{Kg}$. de tilapia cada uno.

En el laboratorio, la materia prima fue inspeccionada organolépticamente empleándose la Tabla de Wittfogel; luego fue sometida a pesado, lavado con agua potable, descamado y fileteado. Los filetes fueron lavados con salmuera salmuera débil, eliminándose previamente el peritoneo de color negro.

Para el salado se empleo sal marítima comercial, tratada a temperatura de $100^{\circ} \mathrm{C}$ durante 30 minutos, con la finalidad de eliminar posibles microorganismos halófilos contaminantes.

Los filetes, de $1 \mathrm{~cm}$. de espesor aproximadamente fueron colocados en recipientes plásticos añadiéndose sal muera saturada preparada con una cantidad de sal equivalente al $40 \%$ en peso de la materia prima. Los recipientes fueron mantenidos a temperatura ambiental, que fluctuó entre 25 y $32^{\circ} \mathrm{C}$, a la sombra, durante el proceso.

Luego del salado, las muestras fueron prensadas durante 12 horas a fin de disminuir la cantidad de agua y posibilitar mejor distribución de sal en los tejidos, Finalizado este tiempo, los filetes fueron extendidos en bandejas con tondo de malla plástica y colocados en un secador solar de cabina, con capacidad para $20 \mathrm{Kg}$. de muestra, con la finalidad de retirar agua hasta un nivel favorable para su conservación. Cuando el nivel requerido de humedad, 25 - 30\% en peso, no era alcanzado en una sola jornada de secado por motivos climatológicos, las muestras eran prensadas para evitar la absorción excesiva de humedad, continuándose con el secado al siguiente día. Las condiciones del aire de secado fueron controladas mediante psicrómetros.

Después del secado los productos fueron colocados en bolsas de polietileno, cada envase con $250 \mathrm{~g}$. y almacenados a temperatura ambiente.

La composición de la materia prima fue determinada de la manera siguiente: proteína, por el método microkjeldahl (6.25 como factor de conversión); grasa, por extracción Soxhlet utilizando éter de petróleo como solvente; humedad, por desecación en estufa a $105^{\circ} \mathrm{C}$ y ceniza por incineración en mufla a $600^{\circ} \mathrm{C}$. Todos los análisis fueron realizados según los métodos de la A.O.A.C. (1980).

Durante el período de salado se realizó análisis de humedad y cloruro de Sodio) (A.O.A.C., 1980) en intervalos de 1 hora, con la finalidad de determinar el tiempo de salado. 
En el producto elaborado se determiné nuevamente la composición química, empleando los mismos métodos utilizados para la materia prima.

Los efectos del salado y secado en las propiedades funcionales de las proteínas fueron verificados por la capacidad de rehidratación del producto seco. La capacidad de rehidratación se determiné por inmersión en agua destilada; y las muestras fueron pesadas en intervalos de 0.5 horas, hasta peso constante.

El examen microbiológico consistió en el recuento de colonias halófilas y de coliformes, siguiendo las recomendaciones de Mossel y Quevedo (1967).

Para evaluar la calidad del producto final se observó las características organolépticas teniendo en consideración el sabor, color, aroma y apariencia general.

Se calculó rendimientos por la razón de peso entre la materia prima y el producto elaborado y expresado en porcentaje.

\section{RESULTADOS Y DISCUSION}

La tilapia utilizada registré longitud total promedio de $22 \mathrm{~cm}$. y peso promedio de $250 \mathrm{~g}$. En la evaluación de frescura se obtuvo un puntaje de 18; es decir, se trabajó con materia prima de muy buena calidad,

Los resultados de la composición química proximal de la materia prima se los presenta en el cuadro 1 .

\section{Cuadro 1}

COMPOSICIÓN QUÍMICA DE LA TILAPIA FRESCA Y PROCESADA

Componente

Fresca

Humedad

Proteína (N x 6.25)

Grasa

Ceniza

80.0

17.3

2.0

0.7

Porcentaje (\%)

Cloruro de sodio
Procesada

25.0

37.0

4.3

33.7

32.2 
En el producto final, el rendimiento promedio en relación a la materia prima es del 14. 1\% (cuadro 2). Este rendimiento está por debajo de los informados para especies marina y de agua dulce saladas y secadas (Sánchez y Lam, 1965; Moncada y Sarmiento, 1982; Lupin, 1978; Hitzchky y Nunes, 1986). Esto se debe al tipo de producto en filetes y no entero o descabezado y al contenido de humedad alcanzado en los filetes de tilapia salada seca $(25 \%)$

\section{Cuadro 2}

\section{RENDIMIENTO DEL PROCESAMIENTO DE SALADO Y SECADO DE TILAPIA (Oreochromis sp.)}

\begin{tabular}{llll}
\hline & Peso $(\mathrm{Kg})$. & $\mathrm{R}^{\prime}$ & $\mathrm{R}$ \\
\hline Entero & 10.00 & & \\
Fileteado & 3.50 & 100.0 & 35.0 \\
Salado & 2.97 & 84.9 & 29.7 \\
Secado (25\% de humedad) & 1.41 & 47.5 & 14.1 \\
\hline
\end{tabular}

La tilapia procesada por el método de salado en salmuera muestra óptimas características de preservación no observándose coloración amarilla, que es índice de enrranciamiento.

Durante la etapa de salado el contenido de humedad fue inversamente proporcional al contenido de cloruro de sodio. El contenido de humedad entre el inicio y el final del salado decrece de $80 \%$ a $62 \%$. El cloruro de sodio, después de 16 horas de salado, alcanza una concentración de $17.6 \%$ en el músculo de tilapia, permaneciendo prácticamente constante hasta el final del salado (gráfico 1). Esto concuerda con lo informado por diferentes investigadores (Sánchez y Lam, 1965; Sánchez, 1975; Moncada y Sarmiento, 1982; Hitzchky y Nunes, 1986).

Costa (1960), citado por Hitzchky y Nunes (1986), analizando varias especies de pescado de Angola observó que luego de ser retirado de los estanques de salado, la humedad variaba de 54 a $62 \%$ y el cloruro de sodio desde 10.1 hasta $21.2 \%$.

En el gráfico 2 se muestra el proceso de secado de la tilapia salada en el secador solar de cabina. En el mismo gráfico se representa la radiación solar incidente sobre el plano del colector y la temperatura del aire en el interior de la 
cámara de secado en función de la hora solar. La circulación del aire en el interior del secador se debió a la convección natural. Las curvas obtenidas tienen similitud con aquellas determinadas por Carbonell et al (1985) y Espeleta et al (1983) para el secado de zanahorias y hongos comestibles, respectivamente, deshidratados en secadores solares. El bajo contenido de humedad alcanzando en el producto deshidratado al cabo de 7 horas de proceso continuo, en un día despejado, es un índice de a eficiencia del secador solar utilizado. En esas condiciones el tiempo de secado debe de ser menor, hasta alcanzar un porcentaje de humedad de 35 a $40 \%$ considerando óptimo (ITP) en 1988.

La composición química del producto elaborado (cuadro 1) es semejante a la encontrada por Moncada y Sarmiento (1982) para el boquichico y bagre salado secos.

Los contenidos promedio de ceniza y humedad, en los productos elaborados, son de $33.7 \%$ y $25 \%$ respectivamente. Gurgel y Freitas (1971), citados por Hitzchky y Nunes (1986), indican como límite máximo de humedad para pescado seco salado, $45 \%$, a fin de lograr una buena conservación.

Uno de los metodos utilizados para verificar la calidad del pescado salado seco es aquel que se basa en la relación sal/humedad; ésta no debe ser inferior a 0.30 (Fuegel y Freitas, 1971; citados por Hitzchky y Nunes, 1986). Moncada y Sarmiento (1982) encontraron valores de 0.91 y 0.80 para la relación sal/humedad, en boquichico y bagre respectivamente. Esta relación para la tilapia seco salada fue de 1.3 aproximadamente, ello indica que el proceso ha sido satisfactorio.

Considerando los resultados obtenidos para la proteína total, cuyo valor promedio fue de $37 \%$ (cuadro 2), se observa que está entre aquellos encontrados en diversas especies de pescado salado, cuyos valores varían entre 24 y $45 \%$ (Sánchez y Lam, 1965); Moncada y Sarmiento, 1982).

La capacidad de rehidratación, indicativa del poder de reabsorción de agua por el producto, alcanza el máximo de $45 \%$ después de 5 horas (gráfico 3 ).

El recuente de halófilas y de coliformes en el producto elaborado arrojó resultados negativos, lo cual indica ja bondad del procesamiento realizado.

El producto seco, evaluado organolépticamente en sus características de aroma, color, sabor y apariencia general obtuvo una calificación de muy bueno y fue comparado favorablemente con el pescado seco salado procesado artesanalmente en la zona.

\section{CONCLUSIONES}

1. El producto salado y seco presento óptimas características de preservación, no observándose coloraciones y olores provenientes de bacterias halófilas, ni rancidez. 
2. El contenido de cloruro de sodio en el músculo de tilapia alcanzó un máximo de $17.6 \%$ luego de 16 horas de inmersión en salmuera.

3. El contenido de humedad fue inversamente proporcional al contenido de cloruro de sodio durante el periodo de salado.

4. Los contenidos de humedad, proteína y ceniza determinados en el producto final, son semejantes a aquellos observados en otras especies sometidas a similar procesamiento.

5. La pérdida de peso de la tilapia salada, durante el período de secado, fue en función del nivel de radiación (hora solar) incidente.

6. Es factible la utilización de secadores solares para el secado de pescado salado, en las condiciones ambientales de la zona.

7. La capacidad de rehidratación del producto salado seco alcanzó el máximo de $45 \%$ luego de un tiempo de inmersión en agua de 5 horas.

\section{BIBLIOGRAFIA}

A.O.A.C. (1980). Methods of Analysis. W. Horowitz, 12 th. ed., 957p

CARBONELL, J.; F. PIÑAGA, y J. PEÑA. (1985). "Deshidratación de Alimentos por energía solar. IV. Ensayos con zanahorias”, en Rev. Agróquim. Tecnolo. Aliment. 25 (1):87.94

DORFMAN, E. (1981). "Pé-Secagem de café en Barcaça con Utilizaçao de Energía Solar". en Rev. bras. de Armaz. 6 (1)" 25-35.

ESPELETA, I. et al. (1983). "Secado solar de hongos comestibles", en Ing. y Ciencia Química. 7(3):35-41.

GRANADOS, 1. (1982). "Análisis del comportamiento de un secador solar usado en el Proceso de Curado-secado de Cebolla”, en Ing. y Ciencia Química, 6(3/4):215.

HITZSCHKY, G. y M. NUNES. (1986). "Salado y Secado del Cangulo. Balistes vetula Linnaeus, en el Estado de Ceará, Brasil”, en Boletim de Ciencias do Mar, N 43, Univ. Fed. de Ceará.

LUPIN, H. (1978). Fundamentos para la elaboración de Merluza salada y seca. La Plata, Centro de Investigaciones de Tecnología Pesquera. 
MARCONDES, J. et al. (1981). "Nova técnica de Secagem solar industrial de Cacau", en Rey. Ceres 28 (155): 19-35.

MONCADA, F. et al. (1978). “Técnicas de bajo costo para la conservación de pescado", en Tecnología $\mathrm{N}^{\circ} 111$, enero/febrero, p. 27-44.

----- y G. SARMIENTO (1982). “Tecnología apropiada en Salazón de pescado, Tecnología apropiada en Salazón de pescado", en Tecnología $\mathrm{N}^{\mathrm{0}} 135$, enero/febrero, p. 7-22.

MOSSEL, D. y F. QUEVEDO (1967). Control Microbiológico de los Alimentos, Lima, CLEIBA, Ed. UNMSM, p. 96.

SANCHEZ, J. R. LAM (1965). "Principios técnicos de salado y secado del pescado. Estudio químico de la sal en el litoral”. Inf. Inst. Mar Peruano, Callao, (9):3-37.

- (1975). “Tecnología del Salado y Secado artificial de la Merluza”. Inf. Inst. Mar Perú, Callao, (43):3-30. 


\section{Grafico 1}

VARIACION DEL CONTENIDO DE HUMEDAD Y CLORURO DE SODIO EN MUSCULO DE TILAPIA. DURANTE EL SALADO EN SALMUERA SATURADA

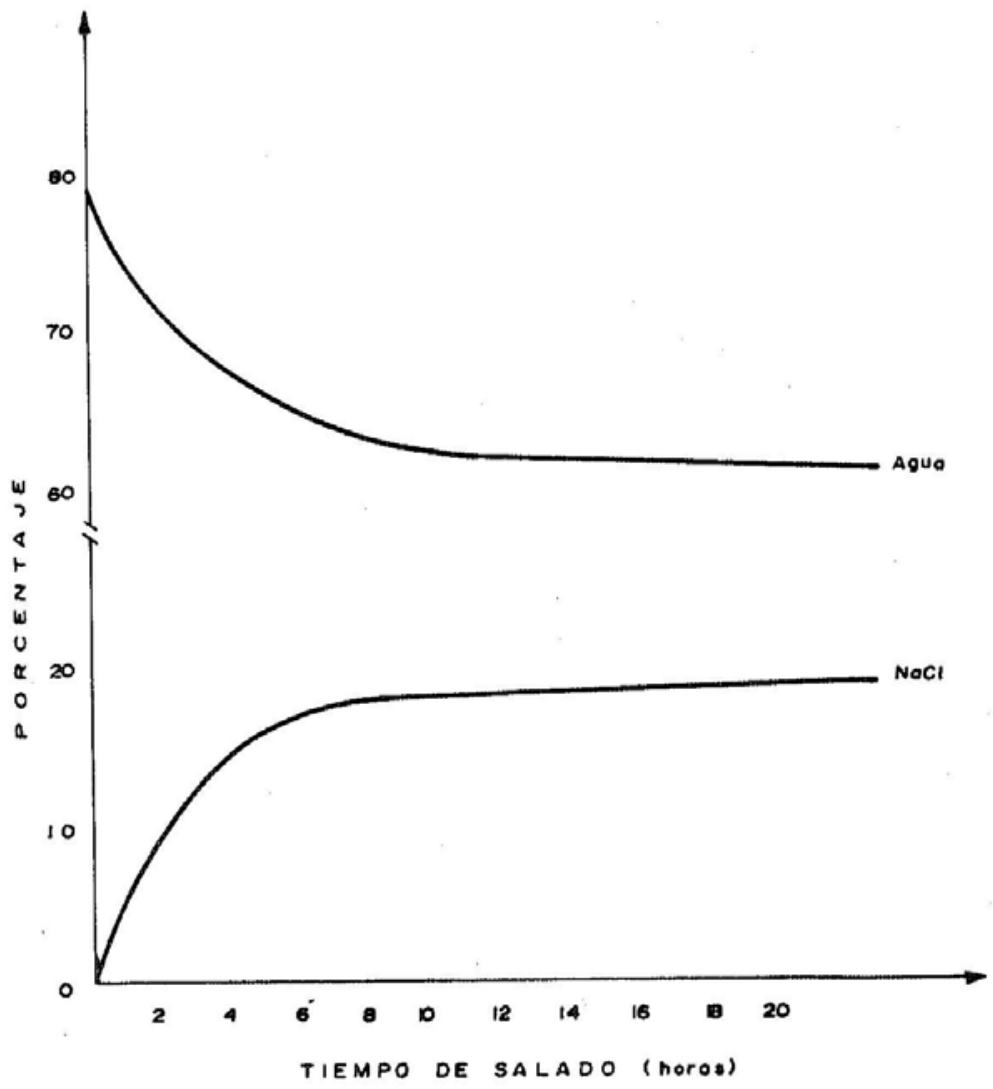




\section{Grafico 2}

VARIACION DEL CONTENIDO DE HUMEDAD DE FILETES DE TELAPIA DE LA TEMPERATURA DEL AIRE DE LA CAMARA DE SECADO Y DE LA RADIACION SOLAR

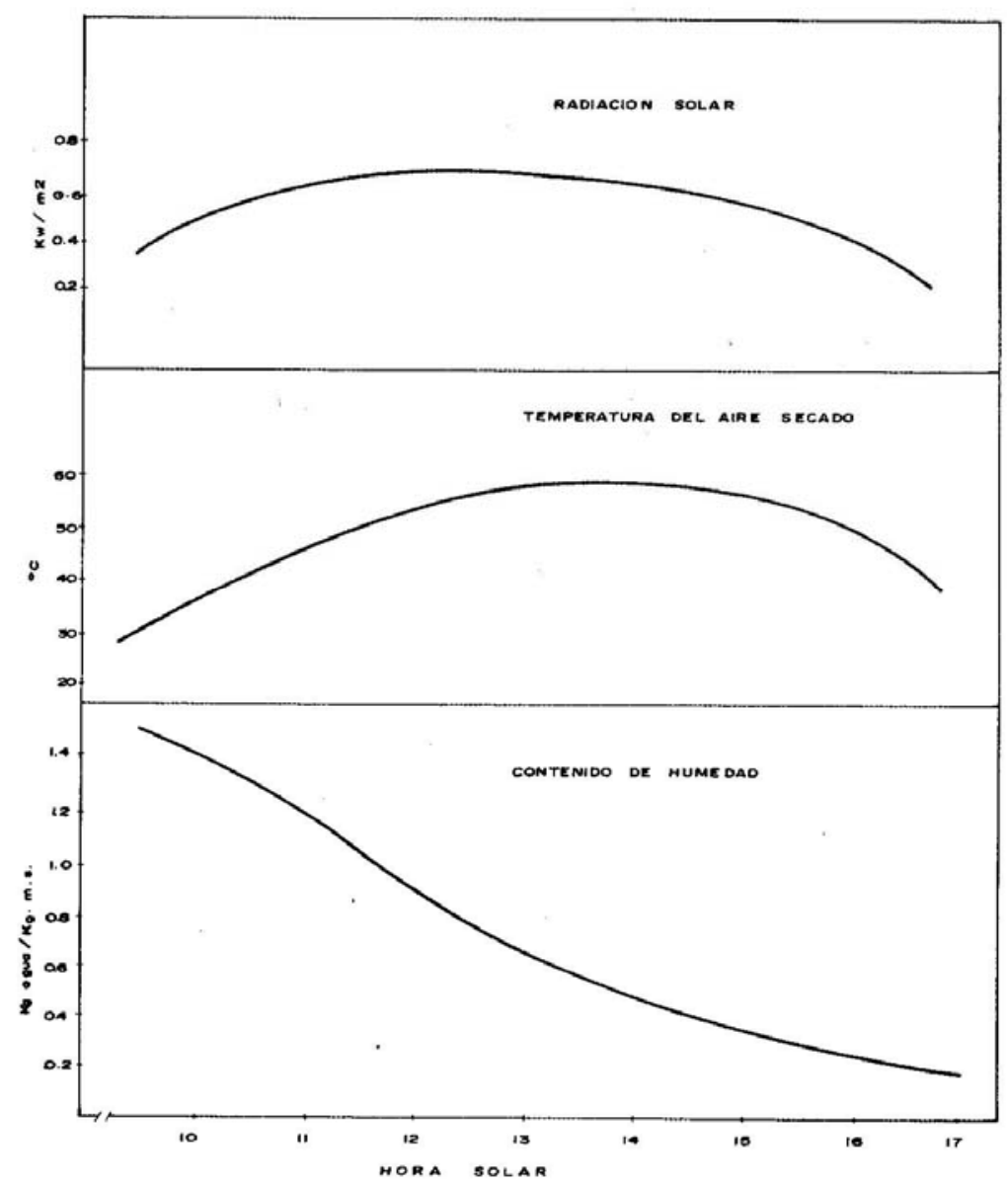




\section{Grafico 3}

CAPACIDAD DE HIDRATACION DE FILETES SECO SALADOS DE TILAPIA

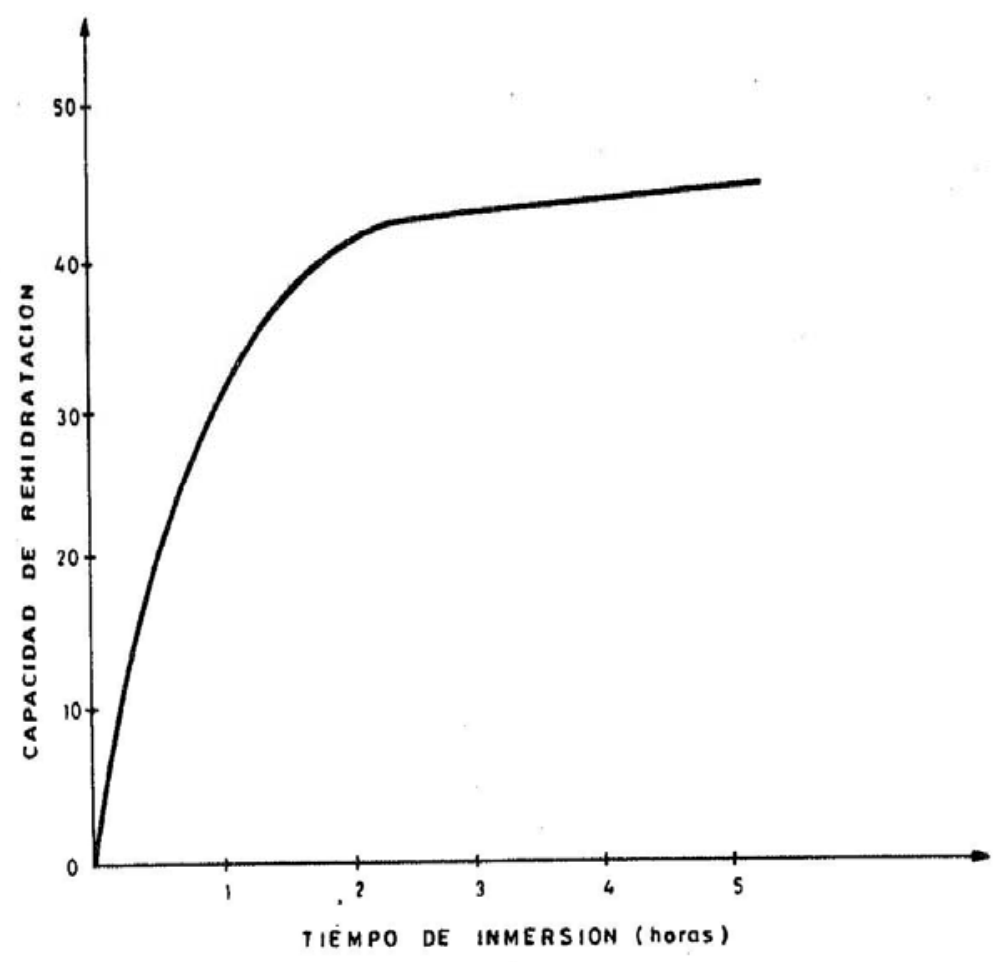

